\title{
Role of Peripheral Immune Response in Microglia Activation and Regulation of Brain Chemokine and Proinflammatory Cytokine Responses Induced During VSV Encephalitis
}

\author{
Christina D. Steel \\ Old Dominion University, csteel@odu.edu \\ Kimberly Breving \\ Susan Tavakoli \\ Woong-Ki Kim \\ Larry D. Sanford
}

See next page for additional authors

Follow this and additional works at: https://digitalcommons.odu.edu/biology_fac_pubs

Part of the Immunology and Infectious Disease Commons, Neurosciences Commons, and the Virology Commons

\section{Repository Citation}

Steel, Christina D.; Breving, Kimberly; Tavakoli, Susan; Kim, Woong-Ki; Sanford, Larry D.; and Ciavarra, Richard P., "Role of Peripheral Immune Response in Microglia Activation and Regulation of Brain Chemokine and Proinflammatory Cytokine Responses Induced During VSV Encephalitis" (2014). Biological Sciences Faculty Publications. 330.

https://digitalcommons.odu.edu/biology_fac_pubs/330

\section{Original Publication Citation}

Steel, C. D., Breving, K., Tavakoli, S., Kim, W. K., Sanford, L. D., \& Ciavarra, R. P. (2014). Role of peripheral immune response in microglia activation and regulation of brain chemokine and proinflammatory cytokine responses induced during VSV encephalitis. Journal of Neuroimmunology, 267(1-2), 50-60. doi:10.1016/j.jneuroim.2013.12.002 
Authors

Christina D. Steel, Kimberly Breving, Susan Tavakoli, Woong-Ki Kim, Larry D. Sanford, and Richard P. Ciavarra 


\title{
Role of peripheral immune response in microglia activation and regulation of brain chemokine and proinflammatory cytokine responses induced during VSV encephalitis
}

\author{
Christina D. Steel ${ }^{\mathrm{a}}$, Kimberly Breving ${ }^{\mathrm{a}}$, Susan Tavakoli ${ }^{\mathrm{a}}$, Woong-Ki Kim ${ }^{\mathrm{a}}$, Larry D. \\ Sanford ${ }^{\mathrm{b}}$, and Richard P. Ciavarra ${ }^{\mathrm{a}, 1}$ \\ aDepartment of Microbiology and Molecular Cell Biology, Eastern Virginia Medical School, \\ Norfolk, VA 23501 \\ ${ }^{b}$ Department of Pathology and Anatomy, Eastern Virginia Medical School, Norfolk, VA 23501
}

\section{Introduction}

\begin{abstract}
Many lethal human pathogens (e.g. rabies, Ebola, and Hendra viruses) can be found in the Order Mononegavirales. These viruses can also have economic impacts because of their ability to infect poultry and cattle (D'Agostino et al., 2012b)Lamb and Parks, 2007; Lyles and Rupprecht, 2007; Planz et al., 2009). Vesicular stomatitis virus (VSV) is a member of the Vesiculovirus genus in the Rhabdoviridae family, one of the four families in the Order Mononegavirales and is the prototypic virus of this family that includes rabies virus. The genome of VSV encodes only five major proteins that nonetheless provide sufficient information to infect a broad range of host cells, shut down cellular protein synthesis and produce productive infections (Das et al., 2008). VSV introduced systemically induces a rapid and potent type I interferon (IFN) response essential for survival (Barchet et al., 2002). Components of the adaptive immune response (antibody, T cells) appear around 6-8 days post infection (PI) and eliminate infectious VSV from peripheral tissues. In the absence of adaptive immunity mice invariably succumb to infection (Thomsen et al., 1997). Unexpectedly, VSV antigen remains in peripheral tissues for almost two months PI despite efficient clearance of infectious VSV from the host (Turner et al., 2007).
\end{abstract}

A single intranasal application of VSV results in infection and viral replication in olfactory neurons with transmission of this neurotropic virus to the olfactory bulb $(\mathrm{OB})$ via the olfactory nerve (Reiss et al., 1998). VSV replicates invasively in the OB penetrating deeper layers of the OB (Reiss et al., 1998) and progresses caudally reaching the hindbrain around day 8 (Huneycutt et al., 1994). CNS invasion by VSV does not go unnoticed as Rig-1 (retinoic acid like receptor-1, (Rieder and Conzelmann, 2009) and toll-like receptor-7 (TLR7 (D'Agostino et al., 2012a, Lund et al., 2004) signaling pathways are engaged resulting in astrocyte and microglia activation and a subsequent astrocytosis and microgliosis (Steel et al., 2009). Neutrophils are the initial inflammatory cell seen in the OB around 1 day PI (Chen et al., 2001) suggesting rapid chemokine production, a view supported by elevated

\footnotetext{
(C) 2013 Elsevier B.V. All rights reserved.

${ }^{1}$ Corresponding author: Dr. Richard P. Ciavarra, Department of Microbiology and Molecular and Cell Biology, Eastern Virginia Medical School, 700 W Olney Road, Norfolk, VA 23501. Phone 757-446-5661; fax 757-624-2255; ciavarrp@evms.edu.

Publisher's Disclaimer: This is a PDF file of an unedited manuscript that has been accepted for publication. As a service to our customers we are providing this early version of the manuscript. The manuscript will undergo copyediting, typesetting, and review of the resulting proof before it is published in its final citable form. Please note that during the production process errors may be discovered which could affect the content, and all legal disclaimers that apply to the journal pertain.
} 
CCL1 and CXCL10 transcripts in the brain detected one day PI (Ireland and Reiss, 2006). Around 6-8 days PI a robust mixed cellular infiltrate dominated by neutrophils, T cells, macrophages and to a lesser extent DCs accumulates in the brain parenchyma (Bi et al., 1995, Ciavarra et al., 2006, Steel et al., 2009, Steel et al., 2008). A number of studies have demonstrated that inhibition of VSV replication, caudal penetration and survivability are dependent on both innate and adaptive effector mechanisms (Huneycutt et al., 1993, Komatsu et al., 1999, Thomsen et al., 1997). It has previously been suggested that VSV encephalitis is $\mathrm{T}$ cell-independent although this view has not been critically tested during either the acute (6-8 days PI) or recovery (10-14 days PI) phases of VSV encephalitis (Frei et al., 1989, Nansen et al., 2000).

The observed activation and expansion of microglia in encephalitic brains is consistent with prior studies in autoimmune and inflammation models suggesting that microglia represent key regulatory cells in the innate and adaptive immune response (Marques et al., 2006, Pope et al., 1998). Furthermore, microglia are reported to up regulate MHC class II and CCR7 at the onset of symptoms and progression of experimental allergic encephalomyelitis collaborating the view that microglia develop into antigen presenting cells (APCs) with migratory potential in the inflamed CNS (Dijkstra et al., 2006). However, under basal conditions the brain parenchyma also contains a trace population of CD11c+cells that may represent antigen-presenting DCs. Most of these cells reside in the juxtavascular parenchyma and not the perivascular spaces. Interestingly, their cellular processes extended into the glia limitans that may allow for presentation of antigens to extravasated $\mathrm{T}$ cells in the perivascular spaces (D'Agostino et al., 2012a). CD11c+ can also be found in the meninges and choroid plexus and at this location they constitutively express MHC class II antigens, unlike parenchymal DCs and microglia (Anandasabapathy et al., 2011, D' Agostino et al., 2012a). In the VSV encephalitis model, both innate and adaptive immune responses were markedly impaired by prior conditional ablation of peripheral DCs (Steel et al., 2009), whereas conditional depletion of peripheral macrophages did not alter VSV encephalitis (Steel et al., 2010). Interestingly, selected depletion of brain perivascular macrophages (bPVMs) inhibited anti-viral immunity and survival (Steel et al., 2010). Thus the precise role these various cell types play in the CNS innate and adaptive anti-viral immune response is poorly defined and remains a contentious issue.

In this study, we describe phenotypic changes on microglia isolated from encephalitic brains that argue against these cells functioning as professional APCs although microglia are clearly activated by VSV. The robust infiltrate characteristic of the acute phase of VSV encephalitis reflects the rapid ( 24 hours PI) global induction of transcripts encoding multiple chemokines and proinflammatory cytokines. Multi-parameter flow cytometric analysis confirmed that activated microglia expressed two CC receptors (CCR4, CCR9) that could contribute to their activated state. In contrast, inflammatory cells were devoid of all tested chemokine receptors with the exception of CCR7. Kinetic analysis revealed that VSVinduced a bimodal chemokine and proinflammatory cytokine mRNA response with a major peak on day 3 followed by a second weaker induction on 7 days PI. Ablation of peripheral DCs or T cells markedly inhibited global chemokine and cytokine transcript levels on 7 days PI. Thus, infiltrating T cells represent not only anti-viral effector cells but may also function to sustain the inflammatory response until infections virus is cleared from the CNS.

\section{Materials and Methods}

\section{Mice and virus infection}

Diphtheria toxin (DT) receptor transgenic (DTRTg) mice (C.FVB-Tg(Itgax-DTR/ EGFP)57Lan/J, Jackson Laboratories Bar Harbor, ME) were bred to C57BL/6 mice (B6, Jackson Laboratories). Transgenic F1 mice were used in all DC depletion studies and are 
referred to as DTRTgF1 mice. b2m-knock out mice (strain B6.129P2-b2m) were purchased from Jackson Laboratories (Bar Harbor, ME) and housed in our animal facility in sterile microisolator cages with sterile food, water and bedding. Wild-type VSV-Indiana strain, provided by Dr. Philip Marcus, University of Connecticut, was grown and assayed as previously described (Marvaldi et al., 1977). Virus was grown in confluent monolayers of Vero cells and virus titers determined by standard plaque assays (Sekellick and Marcus, 1979). VSV was introduced into the brain via intranasal application of 5ul/nostril with $5 \times 10^{4}$ PFU VSV (Barna et al., 1996). All experiments were performed in accordance with federal guidelines and under an Institutional Animal Care and Use Committee-approved protocol.

\section{Cell isolation and depletion}

Brains were excised from perfused (30 ml cold PBS) mice, individually homogenized, pooled and then subjected to discontinuous Percoll centrifugation to enrich for microglia and leukocytes as previously described (Steel et al., 2009). Single cell suspensions of peripheral organs (spleen, draining cervical lymph nodes (CLNs), lung) were scrubbed through 40m nylon mesh cell strainers. Erythrocytes were lysed as necessary using BD PharmLyse Ammonium Chloride lysing reagent (Becton Dickinson, Carlsbad, CA). In vivo ablation of DCs was achieved in DTRTgF1 mice with DT following an established protocol (Ciavarra et al., 2006). Depletion of CD4+ cells was achieved in b2m-knock out mice (CD8-deficient mice). Groups of age-matched mice were treated with anti-mouse CD4 (clone YTS 191, Bio $\mathrm{X}$ Cell, Inc., West Lebonon, $\mathrm{NH}$ ) to deplete their $\mathrm{CD} 4+\mathrm{T}$ cells, or with rat $\mathrm{IgG} 2 \mathrm{~b}$ isotype control (clone LTF-2, Bio X Cells, Inc.). Mice received 100 ug of anti-CD4 or isotype control in sterile PBS by intraperitoneal injection on days $-3,-1,+1,+3$ and were euthanized on day +7 .

\section{Multiparameter Flow Cytometry}

Unless indicated otherwise, monoclonal antibodies (mAbs) against cell surface antigens were purchased from eBioscience (San Diego, CA). Cells were stained and washed in flow cytometry wash buffer (PBS supplemented with $1 \%$ goat serum and $0.1 \%$ sodium azide). The following mAbs were used in this study: CD11b, clone M1/70; CD45, clone 30-F11; MHC II, clone M5/114.15.2; CD11c, clone N418; CD4, clone GK1.5; CD8a, clone 53-6.7; CD45R, clone RA3-6B2; MHC I, clone 34-1-2S; PD-1, clone J43; CD115, clone AFS98; CD40, clone 1C10; CCR1, clone 643854; CCR2, clone 475301; CCR4, clone 2G12; CCR7, clone 4B12; CCR9, clone CD-1.2; CXCR3, clone CXCR3-173; and CD80, clone 16-10A1. Fluorophore conjugates varied based on staining profiles used. Acquisition of 20-200,000 events was performed using a Becton Dickinson (San Diego, CA) FACSCalibur using FlowJo software (Tree Star, Ashland, OR). Non-specific binding in the absence of additional Fc block was previously evaluated and did not affect staining patterns. To determine the absolute number of microglia and infiltrating leukocytes in the CNS, a leukocyte gate was first defined for these cells based on forward and side scatter characteristics. Preliminary studies verified that these gated cells were CD45+ and viable ( $295 \%$ propidium iodide and annexin negative). The percentage of microglia (CD45 low/int) or infiltrating blood cells $\left(\mathrm{CD} 45^{\text {high }}\right)$ within this gate was then used to calculate cell recoveries. All gates and quadrants were established with the use of appropriate isotype controls.

\section{RNA profiles}

Whole brains were removed following perfusion and homogenized in cold PBS. A volume equivalent of $20 \mathrm{mg}$ was removed from each brain homogenate and RNA isolated using the QuickGene RNA tissue kit SII (RT-S2) from FUJIFILM Corporation. RNA profiles were characterized by real-time PCR on RNA isolated either from individual animals or pooled RNA depending on the experiment using a commercial inflammatory cytokine array 
(SABiosciences, catalogue number PAMM-011). Naive (uninfected) mouse brains were used as controls to calculate fold differences in experimental groups.

\section{Results}

\section{Characterization of resident microglia and the cellular infiltrate during the acute phase of VSV encephalitis}

The function of resident microglia and inflammatory cells that penetrate the brain parenchyma during VSV encephalitis remains poorly defined. It is also unclear whether the increased numbers of DCs detected in the encephalitic brain are blod-derived or represent expansion of resident CD11c+ cells (D'Agostino et al., 2012b). To gain insights into potential functions of these various cell types we phenotyped microglia isolated from the brains of uninfected and VSV-infected mice. To determine whether the accumulation of brain DCs (bDCs) seen during VSV encephalitis reflected infiltration of blood-derived DCs, peripheral DCs were ablated with DT prior to infection with VSV. At the peak of the inflammatory response (6-8 days PI), leukocytes were isolated and phenotyped by multicolour flow cytometry. We previously demonstrated VSV infection induced a pronounced CNS infiltrate of CD45 $5^{\text {high }} \mathrm{CD} 11 \mathrm{~b}+$ cells that was clearly distinct from resident CD45 $5^{\text {low/int }}$ CD11b+ microglia (Steel et al., 2009) and Figure 1A). Diphtheria toxin treatment did not deplete microglia but profoundly suppressed the number of inflammatory cells in the brain (panel b). Microglia (gated CD45 ${ }^{\text {low }} \mathrm{CD} 11 \mathrm{~b}+$ ) isolated from uninfected mice were CD115+MHC-1-/low MHC-II-CCR7-CD11C-CD40-CD80-(data not shown). This phenotype remained stable during infection with the exception of MHC class-I antigens (MHC-1) that were upregulated indicating that microglia recognized and responded to the presence of this virus (Figure 1B, panels c, e, g, i). Ablation of peripheral DCs did not alter microglia CD115 (colony stimulating factor receptor-1) expression but suppressed induction of MHC-1 antigens suggesting that optimal microglia activation was dependent on infiltrating DCs (1B, panels $\mathrm{d}, \mathrm{f}, \mathrm{h}, \mathrm{j}$ ). MHC class-II antigens were not detected at this time but are expressed in significant amounts around 10 days PI (Steel et al., 2009). Thus, VSV infection activates microglia in a CCR7- and CD40/CD154-independent fashion during the acute phase of VSV encephalitis. The role of constitutive and sustained expression of microglia CD115 during VSV encephalitis remains to be elucidated. In contrast to microglia, the $\mathrm{CD} 45^{\text {high }} \mathrm{CD} 11 \mathrm{~b}+$ infiltrate was primarily CCR7+CD40+CD115+MHC-1+MHC-II \pm CD $80+$ irrespective of whether they were isolated from normal of DC-depleted hosts (1C, panels k-r). Within the infiltrate gate we detected bDCs $(\mathrm{CD} 11 \mathrm{c}+\mathrm{CD} 11 \mathrm{~b}+\mathrm{CCR} 7+$, panels $\mathrm{k}-\mathrm{j}$ mostly derived from the circulating pool because prior DT treatment decreased the number of bDCs relative to untreated VSV infected transgenic mice $\left(3 \times 10^{4}\right.$ versus $0.94 \times 10^{4} /$ mouse for untreated and DT treated, respectively). These data are consistent with recent studies by Bullock and colleagues (D'Agostino et al., 2012a, D'Agostino et al., 2012b) who reported that in the VSV encephalitis model one of the major bDC subsets is peripherally derived. As reported previously, CD4+ and CD8+ T cells were well represented in the infiltrate including a subset specific for the immunodominant epitope present in the VSV nuclear protein. Depletion of peripheral DCs markedly inhibited infiltration of both CD4+ and CD8+ T cell subsets as well as the CD8+ VSV-specific subset (tetramer+).

\section{Evaluation of microglia as antigen presenting cells during the induction phase of VSV encephalitis}

To determine if costimulatory molecules are transiently expressed on activated microglia we phenotyped microglia for B7 family members as well as 4-1BBL (CD137) at 3 days PI. DTRTg mice were either untreated or depleted of DCs prior to infection to assess the extent to which infiltrating DCs contribute to microglia activation and costimulatory antigen expression. In this study we isolated microglia from the $\mathrm{OB}$ where most of the viral antigen 
rapidly accumulates providing microglia with ample viral antigen for $\mathrm{T}$ cell activation. As expected, OB microglia obtained from naïve (uninfected) mice expressed very low levels of MHC-I antigen and were devoid of MHC-II. In their naïve state they also did not express the costimulatory molecules CD80, CD86, CD137 and CD154 (CD40 ligand) as well as the B7 family members PD-L1/2 (B7-H1/B7-DC) or PD-1, the receptor for these inhibitory ligands (Figure 2A, panels a-e). Although microglia from VSV infected OBs became activated indicated by increased expression of MHC-1 and PD-1, they failed to express any of the evaluated costimulatory molecules (panels f-j). Again, maximum microglia MHC-1 expression was dependent on peripheral DCs, whereas PD-1 expression was normal in these mice (panels k-o). This phenotype was not unique to OB microglia because microglia isolated from the remaining brain also did not express B7 family members (panel B).

\section{Rapid Chemokine and proinflammatory cytokine responses in the CNS following infection with VSV}

Prior studies indicated intranasal application of VSV induced a rapid chemokine response (Ireland and Reiss, 2006) that was followed by the appearance of inflammatory cells (Mac-1+) in the OB around 36 hours PI (Christian et al., 1996, Ireland and Reiss, 2006). To more completely characterize this response, we used a focused inflammatory cytokine qPCR array on OBs from naïve mice and mice infected with VSV one day previously. Figure 3 illustrates that 24 hours PI, several chemokine ligand/receptor pairs were altered by infection. Generally, there was a co-ordinated induction of receptors and their respective chemokine ligands. A similar coordinated induction was also observed for IL-1r1 chain and cytokines IL-1a and IL-1b.

\section{Neurotropic VSV induces a bimodal chemokine and cytokine response in the CNS}

We next examined brain chemokine and proinflammatory cytokines responses during both the acute and recovery phases of VSV encephalitis. This study revealed that VSV generally induced global CC chemokine and cytokine responses with bimodal kinetics with peak RNA levels detected around 3 and 7 days PI. Representative responses are presented in Figure 4 (panel A) where CCL4 and its receptor CCR5 mRNA levels are plotted versus time. Similar responses were observed for cytokines like Spp1 (osteopontin) and the common IL-6 signalling molecule (IL-6st, panel B) as well as CXC and CX3CL1 chemokines (panel C)). To validate that chemokine and cytokine mRNAs were translated, we determined protein levels for chemokines that were robustly induced at the $\mathrm{mRNa}$ level. Using commercial chemokine-specific ELISA kits and the same brain samples from which the RNA profiles were determined in Figure 4, CXCL10 protein levels in uninfected brains were $16.7+0.96$ versus $328.8+7.7 \mathrm{ng} / \mathrm{mg}$ brain protein $(\mathrm{p}=0.001)$ at day 7 PI. Similarly, CCL7 protein levels in uninfected mice were $337.8+24.7$ versus $43,319+6270 \mathrm{pg} / \mathrm{mg}$ brain protein $(\mathrm{p}=0.001)$ also at day $7 \mathrm{PI}$.

\section{Role of the peripheral anti-viral immune response on chemokine and cytokine profiles in the encephalitic brain}

Bimodal kinetics may reflect a contribution by infiltrating leukocytes because VSV escapes into the periphery following intranasal instillation (Simon et al., 2007), induces a peripheral anti-VSV immune response where antigen persists for several months (Turner et al., 2007). We tested this view in mice conditionally ablated of peripheral DCs where the anti-VSV immune response is markedly suppressed (Ciavarra et al., 2006, Steel et al., 2009). Figure 5 indicates that major $\mathrm{CC}(\mathrm{CC} 12,2,7)$ and $\mathrm{CXC}(\mathrm{CXCL} 1,9,10,11)$ chemokine responses were generally blunted in mice depleted of peripheral DCs although CCL12 and CCL2 were the only ones that reached statistical significance (panels A-C). Transcripts for strongly induced proinflammatory cytokines (IFN-g, IL-1b, TNFa) were similarly blunted although none of them reached statistical significance (panel D). Depletion of DCs reduces the 
number of inflammatory cells that infiltrate the brain during the acute phase of VSV encephalitis, an observation consistent with lowered mRNA levels for IL-2rb/IL-2rg and Itgam/Itgb2, molecules typically found on T cells and macrophages, respectively. The failure to completely suppress chemokine and cytokine production in the CNS may reflect either the presence of residual brain inflammatory cells or continued production by resident CNS cells..

\section{Diphtheria toxin treatment suppresses VSV encephalitis without depleting putative antigen presenting cells in the CNS}

Because DT can cross the blood brain barrier (Buch et al., 2005) and microglia and bPVMs may also express low levels of the transgenic DT receptor (Steel et al., 2008), inhibition of brain chemokine production by DT treatment may reflect loss of these putative APC populations with known chemokine-producing capabilities (D'Agostino et al., 2012a, del Rio et al., 2008). In addition, the blood brain barrier does not protect choroid plexus DCs thereby potentially exposing them to circulating DT. These cells appear to be more related to conventional splenic CD8+ DCs than microglia based on gene expression profiles as well as several other criteria (D'Agostino et al., 2012a). However, DT treatment did not appear to diminish choroid plexus DCs (Figure 6, panels A, B, G), parenchymal DCs (panels C, D) or microglia/bPVMs (panels E, F).

\section{Chemokine profiles in the CNS are suppressed in T cell deficient mice during the acute phase of VSV encephalitis}

To directly test the contribution of infiltrating T cells to the brain anti-VSV chemokine and pro-inflammatory cytokine response, $\mathrm{B}_{2} \mathrm{M}$ knockout mice were depleted of $\mathrm{CD} 4+$ cells and then given VSV. Relative to normal B6 mice subjected to the same injection schedule but given isotype-matched $\mathrm{IgG}, \mathrm{T}$ cell-depleted mice mounted blunted chemokine responses to VSV (Figure 7, panels A, B). Transcripts for chemokine receptors were also markedly reduced in T cell-deficient mice although none reached statistical significance (panel C). Blunted profiles were also seen for multiple cytokines and cytokine receptors (panels C, data not shown). The failure to significantly blunt all chemokine/cytokine responses may reflect the residual contribution of CNS resident cells because few T cells could be detected in the brains of mice treated with anti-CD4 mAb. For example, there was an $80 \%$ reduction in the percentage of $\mathrm{T}$ cells that infiltrated the brain of anti-CD4 treated mice. When absolute numbers of $\mathrm{T}$ cells were calculated the reduction was even more extensive (1762 versus $52=$ 97\% reduction, panels E, F). Thus these data indicate that infiltrating T cells contribute significantly to the second wave of brain chemokine/cytokine production. They further indicate that blood-derived DCs do not contribute to this response since they remain intact following $\mathrm{T}$ cell depletion.

\section{Chemokine receptor expression on microglia and inflammatory leukocytes during VSV encephalitis}

In view of the robust and complex chemokine response induced by VSV neuroinvasion, we sought to identify what chemokine(s) is responsible for the observed microgliosis and accumulation of inflammatory cells. We therefore determined chemokine receptor profiles on microglia and the infiltrate obtained from mice infected 7 days previously with VSV. It is apparent from Figure 8 that microglia $\left(\mathrm{CD} 45^{\text {low }} \mathrm{CD} 11 \mathrm{~b}+\mathrm{F} 4 / 80+\right)$ isolated from naïve mice did not express CCR1, CCR2, and CXCR3, whereas approximately 50\% expressed CCR4 and CCR9 (Figure 8, panels a-d). The vast majority of microglia isolated during acute phase of VSV encephalitis were CCR4+CCR9+. Although we detected a small subpopulation of dimly CXCR3+ microglia in this experiment, in 3 other experiments microglia from VSV infected brains remained CXCR3- (panels e-h and data not shown)). VSV did not induce expression of CCR1 or CCR2 (panels e-h and data not shown). With the exception of CCR7, 
none of the inflammatory cells (neutrophils, macrophages, $\mathrm{T}$ cells) expressed significant levels of any of the other evaluated chemokine receptors (panels j-o, data not shown). Thus, chemokines that signal via CCR1, CCR2, CCR4, CCR9 or CXCR3 do not direct inflammatory cells into the VSV-infected brain.

\section{Discussion}

Of the resident CNS cells with immunological capacity, microglia are widely regarded as the most critical and represent approximately $10-20 \%$ of the brain parenchyma (Havenith et al., 1998, Lawson et al., 1990, Rock et al., 2004, Santambrogio et al., 2001, Town et al., 2005). They purportedly orchestrate inflammatory responses by the selective release of chemokines (Meda et al., 1999) and enhance pathogen clearance as APCs (Pozzi et al., 2005). APC function has also been ascribed to parenchymal and choroid plexus CD11c+ DCs (D'Agostino, Gottfried-Blackmore, 2012a, D'Agostino, Kwak, 2012b) as well as bPVMs (Polfliet et al., 2002, Polfliet et al., 2001, Steel et al., 2010). However, microglia isolated form uninfected or encephalitic brains failed to express molecules essential for display of antigenic peptides (MHC-1/II) or delivery of costimulatory signals. VSV-specific naïve $\mathrm{T}$ cells primarily receive their costimulation via $\mathrm{B} 7$ family members $\mathrm{CD} 80 / \mathrm{CD} 86$ (McAdam et al., 2000) and to a lesser extent CD137 (Vinay et al., 2003) and CD40 (Andreasen et al., 2000, D'Aversa et al., 2008). Activated microglia isolated from OB, a region where VSV accumulates and replicates, still failed to express these molecules during the induction and acute phases of encephalitis (Forger et al., 1991). We also did not find CCR7 expression under normal or inflammatory conditions suggesting that in the VSV encephalitis model, microglia do not migrate to draining lymph nodes to function as APCs. These data are in contrast with what is observed in the experimental allergic encephalomyelitis (EAE) model where CCR7, CD86 and CD40 expression was detected on microglia (Ponomarev et al., 2005). This difference in these two models may reflect different inflammatory environments that impact microglia biology. Interestingly, deHass (de Haas et al., 2008) reported regional expression of CD80, CD86 and CD40 on microglia from uninfected brains. In our studies we assessed microglia isolated from whole brains because VSV does not remain localized to the OB. Thus, low levels of regional expression may have gone undetected in our studies. However, it should be noted that the one region that we did evaluate, namely the $\mathrm{OB}$, remained nega tive for costimulatory antigen expression and this region was not evaluated in the deHass ${ }^{i}$ study.

Using a RNase protection assay, Reiss and colleagues (Ireland and Reiss, 2006) reported that CCL1 and CXCL10 RNA transcripts were induced in the OB within one day PI with VSV, a response that preceded the appearance of inflammatory cells in the OB. Our study using a real-time PCR array to quantify and more completely characterize this response, are consistent with these initial studies. A number of chemokine RNAs were elevated and likely responsible for orchestrating the mixed cellular infiltrate characteristic of VSV encephalitis as well as inducing microglia activation and expansion. With respect to microglia activation, a subset constitutively expressed CCR4 and CCR9 and could therefore become rapidly activated as soon as threshold levels of CCL3 and CCL25 were achieved, respectively. In peripheral tissues CCL21 stimulates through CCR7 binding but in the brain CCL21 engagement of CXCR3 has been reported to activate microglia (Kallfass et al.). This is not an alternative pathway for microglia activation because VSV did not induce expression of CXCR3 protein on microglia. However, a role for CXCL10 in VSV encephalitis cannot be excluded because CXCR3 mRNA is elevated, VSV is cytopathic for neurons (Faulkner et al., 1979) and damaged neurons release CCL21 (Biber et al., 2001). We did detect transcripts for CCL1 at 24 hours PI but unlike prior published studies (Ireland and Reiss, 2006), this response was relatively weak and not sustained (data not shown). These data 
therefore suggest that microglia activation and expansion is likely driven by multiple chemokines signalling via CCR4 and CCR9 in response to neuroinvasion by VSV.

Neutrophils (CD45 ${ }^{\text {high }} \mathrm{Gr}-1+\mathrm{F} 4 / 80$-) represent the major cell type recruited into the brain during the peak of the inflammatory response. The chemokine(s) responsible for their influx remains to be identified. Both CCL3 and CCL25 are reported to recruits monocytes/ macrophages (Nakamoto et al., 2012, Tran et al., 1998) and as discussed above RNA transcripts for these chemokines as well as their receptors CCR4 and CCR9 were elevated on 1 day PI. However, infiltrating neutrophils did not express CCR1, 2, 4, 9 and only a variable subpopulation (0-25\%) expressed CXCR3 in the encephalitic brain. T cells (CD4 and CD8+) also make a significant contribution to the infiltrate. Although transcripts for the $\mathrm{T}$ cell chemokine CCL17 were rapidly induced and sustained during VSV encephalitis, infiltrating T cells did not express its receptor CCR4 (manuscript in preparation). The most likely candidate for the directed migration of inflammatory cells into the brain parenchyma is CCR7. As demonstrated herein, CCR7 was expressed on the majority of inflammatory cells on 7 days PI and preliminary studies indicate that mRNA for one of its ligands, CCL19, was rapidly induced (5-fold induction) at 48 hours PI. Furthermore, elevated CCL19 transcript levels remained sustained throughout the acute and recovery phases of VSV encephalitis (data not shown). Ongoing neutralization studies are designed to determine th e extent to the VSV-induced infiltrate is CCR7-dependent.

At the peak of the inflammatory response (days 6-8) chemokine responses were more robust relative to day $1 \mathrm{PI}$ with additional chemokines and cytokines recruited into the response. We observed similar blunted chemokine and cytokine responses in the brains of VSV infected mice on 7 days PI following conditional DC ablation or T cell depletion. These similar profiles were likely due to the markedly reduced expansion of $\mathrm{T}$ cells in peripheral lymphoid organs in mice rendered deficient of DCs (Steel et al., 2009). Thus, the DCdepleted host generates fewer activated T cells including tetramer+ VSV-specific T cells that can subsequently invade the VSV infected brain. T cells most likely represent the primary cellular source of chemokines and proinflammatory cytokines at this time point although a T cell-glial interaction essential for glial chemokine production cannot be excluded. Residual chemokine and cytokine production in mice depleted of T cells may reflect the ongoing contribution of CNS resident cells. Consistent with this view, a number of viral pathogens have been shown to induce cytokine production in resident astrocytes (Phares et al., 2013), microglia (Marques et al., 2006) and neurons (Horta et al., 2011).

In summary, we demonstrate herein that VSV neuroinvasion induces a rapid and complex bimodal brain chemokine and proinflammatory cytokine response. CNS resident and infiltrating T cells likely contribute to the initial and second wave of chemokine/cytokine production, respectively. In the encephalitic brain microglia rapidly convert from a resting (CD45 ${ }^{\text {low }} \mathrm{CD} 11 \mathrm{~b}+\mathrm{F} 4 / 80+\mathrm{Gr}-1-\mathrm{CD} 80-\mathrm{CD} 86-\mathrm{CD} 40 \mathrm{~L}-\mathrm{PD}-1-\mathrm{PD}-\mathrm{L} 1 / 2-\mathrm{CCR} 1-\mathrm{CCR} 2-\mathrm{CR} 4 \pm$ $(\sim 50 \%)$ CCR7-CCR9+( $50 \%)$ CXCR3-) to an activated phenotype that includes CCR4 and CCR9 expression on the vast majority of microglia as well as previously reported inductions (MHC-1/II, PD-1). We suggest that constitutive expression of CCR4 and CCR9 may allow microglia to respond quickly to rapidly induced CCR4 (CCL2, 3, 17, 22) and CCR9 (CCL25) ligands, respectively. Although activated microglia express MHC-I/II antigens, their precise role in the anti-VSV adaptive immune response remains to be clarified. We also suggest that the accumulation of a robust mixed cellular infiltrate most likely reflects the sustained production of brain CCL19 and CCR7 expression on brain inflammatory cells. Thus, clearance of this viral pathogen requires the coordinated induction of a brain inflammatory response as well as a peripheral antiviral adaptive immune response to insure efficient viral clearance from the CNS. 


\section{References}

Anandasabapathy N, VAictora GD, Meredith M, Feder R, Dong B, Kluger C, et al. Flt3L controls the development of radiosensitive dendritic cells in the meninges and choroid plexus of the steady-state mouse brain. J Exp Med. 2011; 208:1695-705. [PubMed: 21788405]

Andreasen SO, Christensen JE, Marker O, Thomsen AR. Role of CD40 ligand and CD28 in induction and maintenance of antiviral CD8+ effector T cell responses. J Immunol. 2000; 164:3689-97. [PubMed: 10725727]

Barchet W, Cella M, Odermatt B, Asselin-Paturel C, Colonna M, Kalinke U. Virus-induced interferon alpha production by a dendritic cell subset in the absence of feedback signaling in vivo. J Exp Med. 2002; 195:507-16. [PubMed: 11854363]

Barna M, Komatsu T, Bi Z, Reiss CS. Sex differences in susceptibility to viral infection of the central nervous system. J Neuroimmunol. 1996; 67:31-9. [PubMed: 8707928]

Bi Z, Barna M, Komatsu T, Reiss CS. Vesicular stomatitis virus infection of the central nervous system activates both innate and acquired immunity. J Virol. 1995; 69:6466-72. [PubMed: 7545248]

Biber K, Sauter A, Brouwer N, Copray SC, Boddeke HW. Ischemia-induced neuronal expression of the microglia attracting chemokine Secondary Lymphoid-tissue Chemokine (SLC). Glia. 2001; 34:121-33. [PubMed: 11307161]

Buch T, Heppner FL, Tertilt C, Heinen TJ, Kremer M, Wunderlich FT, et al. A Cre-inducible diphtheria toxin receptor mediates cell lineage ablation after toxin administration. Nat Methods. 2005; 2:419-26. [PubMed: 15908920]

Chen N, Restivo A, Reiss CS. Leukotrienes play protective roles early during experimental VSV encephalitis. J Neuroimmunol. 2001; 120:94-102. [PubMed: 11694324]

Christian AY, Barna M, Bi Z, Reiss CS. Host immune response to vesicular stomatitis virus infection of the central nervous system in C57BL/6 mice. Viral Immunol. 1996; 9:195-205. [PubMed: 8890478]

Ciavarra RP, Stephens A, Nagy S, Sekellick M, Steel C. Evaluation of immunological paradigms in a virus model: are dendritic cells critical for antiviral immunity and viral clearance? J Immunol. 2006; 177:492-500. [PubMed: 16785546]

D'Agostino PM, Gottfried-Blackmore A, Anandasabapathy N, Bulloch K. Brain dendritic cells: biology and pathology. Acta Neuropathol. 2012a; 124:599-614. [PubMed: 22825593]

D’Agostino PM, Kwak C, Vecchiarelli HA, Toth JG, Miller JM, Masheeb Z, et al. Viral-induced encephalitis initiates distinct and functional CD103+CD11b+ brain dendritic cell populations within the olfactory bulb. Proc Natl Acad Sci U S A. 2012b; 109:6175-80. [PubMed: 22474352]

D'Aversa TG, Eugenin EA, Berman JW. CD40-CD40 ligand interactions in human microglia induce CXCL8 (interleukin-8) secretion by a mechanism dependent on activation of ERK1/2 and nuclear translocation of nuclear factor-kappaB (NFkappaB) and activator protein-1 (AP-1). J Neurosci Res. 2008; 86:630-9. [PubMed: 17918746]

Das S, Mishra MK, Ghosh J, Basu A. Japanese Encephalitis Virus infection induces IL-18 and IL-1beta in microglia and astrocytes: correlation with in vitro cytokine responsiveness of glial cells and subsequent neuronal death. J Neuroimmunol. 2008; 195:60-72. [PubMed: 18374991]

de Haas AH, Boddeke HW, Biber K. Region-specific expression of immunoregulatory proteins on microglia in the healthy CNS. Glia. 2008; 56:888-94. [PubMed: 18338796]

del Rio ML, Rodriguez-Barbosa JI, Bolter J, Ballmaier M, Dittrich-Breiholz O, Kracht M, et al. CX3CR1+ c-kit+ bone marrow cells give rise to CD103+ and CD103-dendritic cells with distinct functional properties. J Immunol. 2008; 181:6178-88. [PubMed: 18941208]

Dijkstra IM, de Haas AH, Brouwer N, Boddeke HW, Biber K. Challenge with innate and protein antigens induces CCR7 expression by microglia in vitro and in vivo. Glia. 2006; 54:861-72. [PubMed: 16977602]

Faulkner G, Dubois-Dalcq M, Hooghe-Peters E, McFarland HF, Lazzarini RA. Defective interfering particles modulate VSV infection of dissociated neuron cultures. Cell. 1979; 17:979-91. [PubMed: 226268] 
Forger JM 3rd, Bronson RT, Huang AS, Reiss CS. Murine infection by vesicular stomatitis virus: initial characterization of the H-2d system. J Virol. 1991; 65:4950-8. [PubMed: 1651414]

Frei K, Malipiero UV, Leist TP, Zinkernagel RM, Schwab ME, Fontana A. On the cellular source and function of interleukin 6 produced in the central nervous system in viral diseases. Eur J Immunol. 1989; 19:689-94. [PubMed: 2543584]

Havenith CE, Askew D, Walker WS. Mouse resident microglia: isolation and characterization of immunoregulatory properties with naive CD4+ and CD8+ T-cells. Glia. 1998; 22:348-59. [PubMed: 9517567]

Horta BL, Gigante DP, Nazmi A, Silveira VM, Oliveira I, Victora CG. Maternal smoking during pregnancy and risk factors for cardiovascular disease in adulthood. Atherosclerosis. 2011; 219:815-20. [PubMed: 21885051]

Huneycutt BS, Bi Z, Aoki CJ, Reiss CS. Central neuropathogenesis of vesicular stomatitis virus infection of immunodeficient mice. J Virol. 1993; 67:6698-706. [PubMed: 8105106]

Huneycutt BS, Plakhov IV, Shusterman Z, Bartido SM, Huang A, Reiss CS, et al. Distribution of vesicular stomatitis virus proteins in the brains of BALB/c mice following intranasal inoculation: an immunohistochemical analysis. Brain Res. 1994; 635:81-95. [PubMed: 8173982]

Ireland DD, Reiss CS. Gene expression contributing to recruitment of circulating cells in response to vesicular stomatitis virus infection of the CNS. Viral Immunol. 2006; 19:536-45. [PubMed: 16987071]

Kallfass C, Ackerman A, Lienenklaus S, Weiss S, Heimrich B, Staeheli P. Visualizing production of beta interferon by astrocytes and microglia in brain of la crosse virus-infected mice. J Virol. 86:11223-30. [PubMed: 22875966]

Komatsu T, Ireland DD, Chen N, Reiss CS. Neuronal expression of NOS-1 is required for host recovery from viral encephalitis. Virology. 1999; 258:389-95. [PubMed: 10366576]

Lawson LJ, Perry VH, Dri P, Gordon S. Heterogeneity in the distribution and morphology of microglia in the normal adult mouse brain. Neuroscience. 1990; 39:151-70. [PubMed: 2089275]

Lund JM, Alexopoulou L, Sato A, Karow M, Adams NC, Gale NW, et al. Recognition of singlestranded RNA viruses by Toll-like receptor 7. Proc Natl Acad Sci U S A. 2004; 101:5598-603. [PubMed: 15034168]

Marques CP, Hu S, Sheng W, Lokensgard JR. Microglial cells initiate vigorous yet non-protective immune responses during HSV-1 brain infection. Virus Res. 2006; 121:1-10. [PubMed: 16621100]

Marvaldi JL, Lucas-Lenard J, Sekellick MJ, Marcus PI. Cell killing by viruses. IV. Cell killing and protein synthesis inhibition by vesicular stomatitis virus require the same gene functions. Virology. 1977; 79:267-80. [PubMed: 194405]

McAdam AJ, Farkash EA, Gewurz BE, Sharpe AH. B7 costimulation is critical for antibody class switching and CD8(+) cytotoxic T-lymphocyte generation in the host response to vesicular stomatitis virus. J Virol. 2000; 74:203-8. [PubMed: 10590107]

Meda L, Baron P, Prat E, Scarpini E, Scarlato G, Cassatella MA, et al. Proinflammatory profile of cytokine production by human monocytes and murine microglia stimulated with betaamyloid[25-35]. J Neuroimmunol. 1999; 93:45-52. [PubMed: 10378868]

Nakamoto N, Ebinuma H, Kanai T, Chu PS, Ono Y, Mikami Y, et al. CCR9+ macrophages are required for acute liver inflammation in mouse models of hepatitis. Gastroenterology. 2012; 142:366-76. [PubMed: 22079594]

Nansen A, Marker O, Bartholdy C, Thomsen AR. CCR2+ and CCR5+ CD8+ T cells increase during viral infection and migrate to sites of infection. Eur J Immunol. 2000; 30:1797-806. [PubMed: 10940868]

Phares TW, Stohlman SA, Hinton DR, Bergmann CC. Astrocyte derived CXCL10 drives Accumulation of Antibody Secreting Cells in the Central Nervous System during Viral Encephalomyelitis. J Virol. 2013

Polfliet MM, van de Veerdonk F, Dopp EA, van Kesteren-Hendrikx EM, van Rooijen N, Dijkstra CD, et al. The role of perivascular and meningeal macrophages in experimental allergic encephalomyelitis. J Neuroimmunol. 2002; 122:1-8. [PubMed: 11777538] 
Polfliet MM, Zwijnenburg PJ, van Furth AM, van der Poll T, Dopp EA, Renardel de Lavalette C, et al. Meningeal and perivascular macrophages of the central nervous system play a protective role during bacterial meningitis. J Immunol. 2001; 167:4644-50. [PubMed: 11591794]

Ponomarev ED, Shriver LP, Maresz K, Dittel BN. Microglial cell activation and proliferation precedes the onset of CNS autoimmunity. J Neurosci Res. 2005; 81:374-89. [PubMed: 15959904]

Pope JG, Vanderlugt CL, Rahbe SM, Lipton HL, Miller SD. Characterization of and functional antigen presentation by central nervous system mononuclear cells from mice infected with Theiler's murine encephalomyelitis virus. J Virol. 1998; 72:7762-71. [PubMed: 9733812]

Pozzi LA, Maciaszek JW, Rock KL. Both dendritic cells and macrophages can stimulate naive CD8 T cells in vivo to proliferate, develop effector function, and differentiate into memory cells. $\mathrm{J}$ Immunol. 2005; 175:2071-81. [PubMed: 16081773]

Reiss CS, Plakhov IV, Komatsu T. Viral replication in olfactory receptor neurons and entry into the olfactory bulb and brain. Ann N Y Acad Sci. 1998; 855:751-61. [PubMed: 9929681]

Rieder M, Conzelmann KK. Rhabdovirus evasion of the interferon system. J Interferon Cytokine Res. 2009; 29:499-509. [PubMed: 19715459]

Rock RB, Gekker G, Hu S, Sheng WS, Cheeran M, Lokensgard JR, et al. Role of microglia in central nervous system infections. Clin Microbiol Rev. 2004; 17:942-64. table of contents. [PubMed: 15489356]

Santambrogio L, Belyanskaya SL, Fischer FR, Cipriani B, Brosnan CF, Ricciardi-Castagnoli P, et al. Developmental plasticity of CNS microglia. Proc Natl Acad Sci U S A. 2001; 98:6295-300. [PubMed: 11371643]

Sekellick MJ, Marcus PI. Persistent infection. II. Interferon-inducing temperature-sensitive mutants as mediators of cell sparing: possible role in persistent infection by vesicular stomatitis virus. Virology. 1979; 95:36-47. [PubMed: 220798]

Simon ID, Publicover J, Rose JK. Replication and propagation of attenuated vesicular stomatitis virus vectors in vivo: vector spread correlates with induction of immune responses and persistence of genomic RNA. J Virol. 2007; 81:2078-82. [PubMed: 17151110]

Steel CD, Hahto SM, Ciavarra RP. Peripheral dendritic cells are essential for both the innate and adaptive antiviral immune responses in the central nervous system. Virology. 2009; 387:117-26. [PubMed: 19264338]

Steel CD, Kim WK, Sanford LD, Wellman LL, Burnett S, Van Rooijen N, et al. Distinct macrophage subpopulations regulate viral encephalitis but not viral clearance in the CNS. J Neuroimmunol. 2010; 226:81-92. [PubMed: 20599280]

Steel CD, Stephens AL, Hahto SM, Singletary SJ, Ciavarra RP. Comparison of the lateral tail vein and the retro-orbital venous sinus as routes of intravenous drug delivery in a transgenic mouse model. Lab Anim (NY). 2008; 37:26-32. [PubMed: 18094699]

Thomsen AR, Nansen A, Andersen C, Johansen J, Marker O, Christensen JP. Cooperation of B cells and $\mathrm{T}$ cells is required for survival of mice infected with vesicular stomatitis virus. Int Immunol. 1997; 9:1757-66. [PubMed: 9418136]

Town T, Nikolic V, Tan J. The microglial "activation" continuum: from innate to adaptive responses. J Neuroinflammation. 2005; 2:24. [PubMed: 16259628]

Tran EH, Hoekstra K, van Rooijen N, Dijkstra CD, Owens T. Immune invasion of the central nervous system parenchyma and experimental allergic encephalomyelitis, but not leukocyte extravasation from blood, are prevented in macrophage-depleted mice. J Immunol. 1998; 161:3767-75. [PubMed: 9759903]

Turner DL, Cauley LS, Khanna KM, Lefrancois L. Persistent antigen presentation after acute vesicular stomatitis virus infection. J Virol. 2007; 81:2039-46. [PubMed: 17151119]

Vinay DS, Wolisi GO, Yu KY, Choi BK, Kwon BS. Immunity in the absence of CD28 and CD137 (4-1BB) molecules. Immunol Cell Biol. 2003; 81:176-84. [PubMed: 12752681] 


\section{Highlights}

- We study the murine VSV encephalitis model to understand how a neurotropic viral pathogen is cleared from the brain

- Neuroinvasion induces chemokine receptor expression on microglia but not costimulatory molecules

- Chemokine and proinflammatory cytokine responses in the CNS are robust, complex and biphasic

- Second wave of brain chemokine/cytokine production is dependent on a peripheral immune response and infiltrating $\mathrm{T}$ cells 


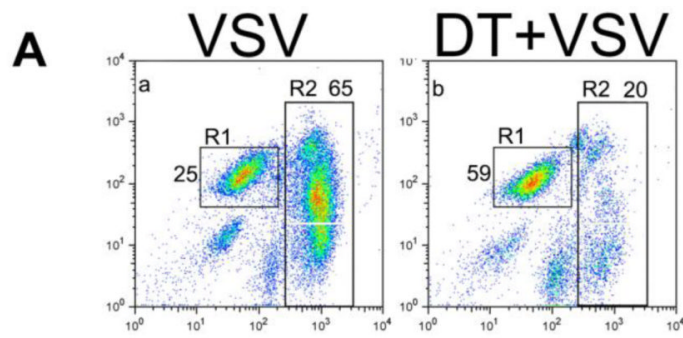

\section{Microglia}
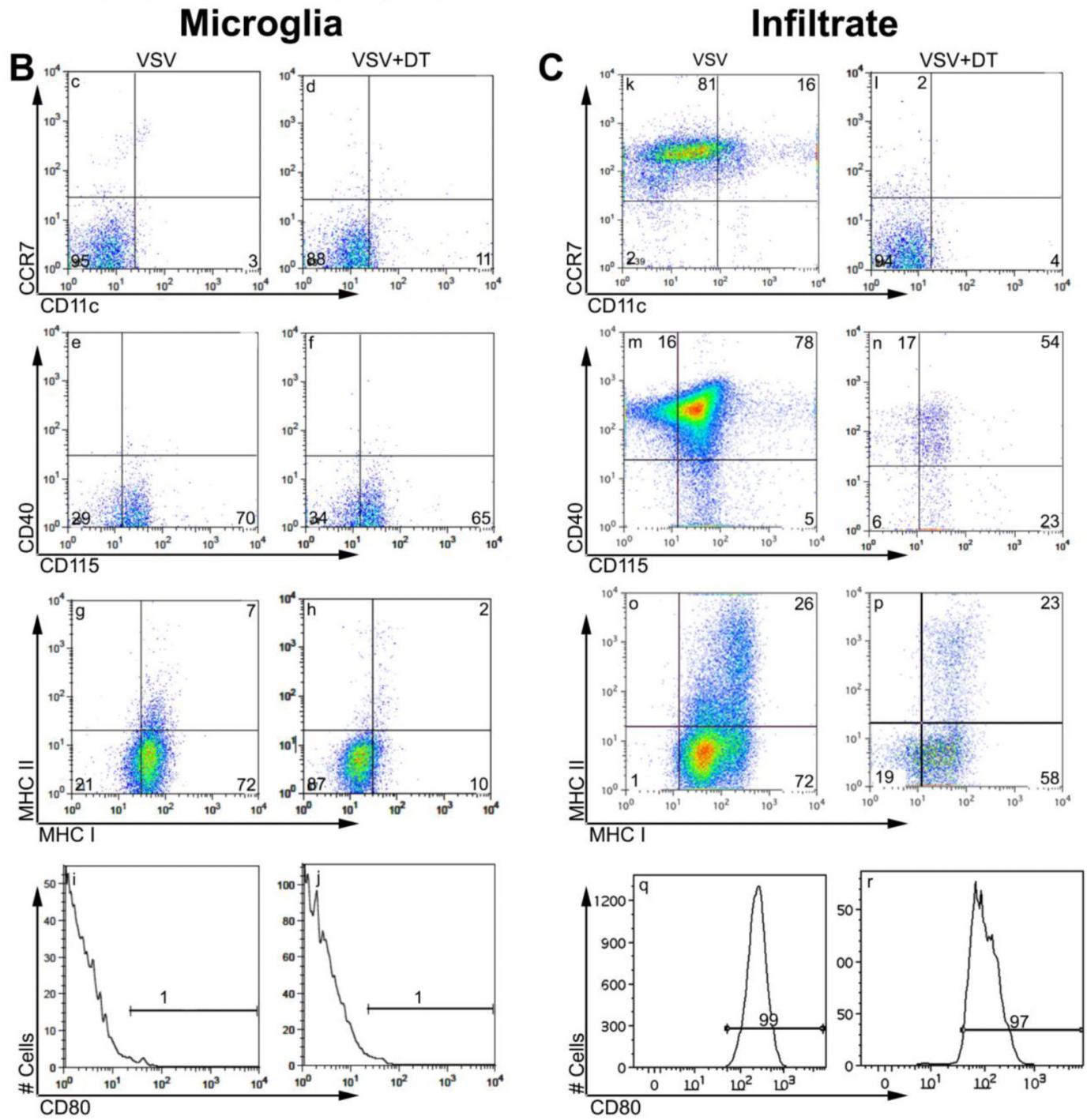

Figure 1.

Phenotypic characterization of microglia and inflammatory cells isolated during the acute phase of VSV encephalitis. DTRTg F1 mice were given DT one day before and after intranasal application of VSV. Control non-DTRTg mice were either not infected (naïve) or given just VSV (4-5 mice/group). Six days PI, brains from each group were pooled, minced and single cell suspension of brain tissue banded on a 70\% Percoll cushion. Microglia and brain leukocytes banded at the 30-70\% Percoll interface were collected, labeled with the indicated $\mathrm{mAbs}$ and then phenotyped by 4-color flow cytometry. Microglia were gated as CD45 ${ }^{\text {low/int }} \mathrm{CD} 11 \mathrm{~b}+$ (panel A, R1 gate), whereas inflammatory cells were defined as $\mathrm{CD} 45^{\text {high }} \mathrm{CD} 11 \mathrm{~b}+$ cells (R2 gate). Co-expression of the indicated molecules on gated 
microglia (B) or inflammatory cells (C) isolated from brains of either normal or DCdepleted, VSV infected mice. 

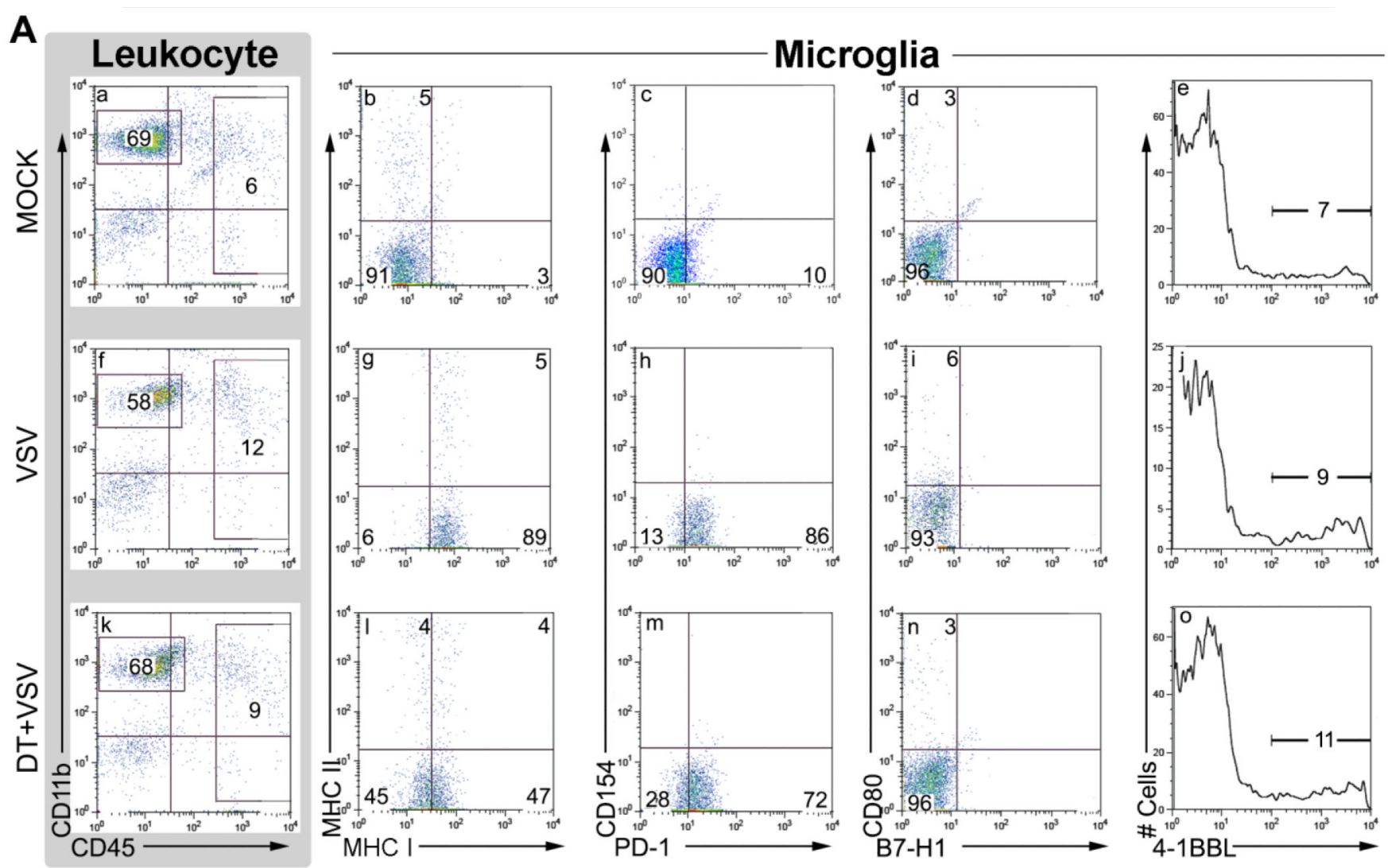

B

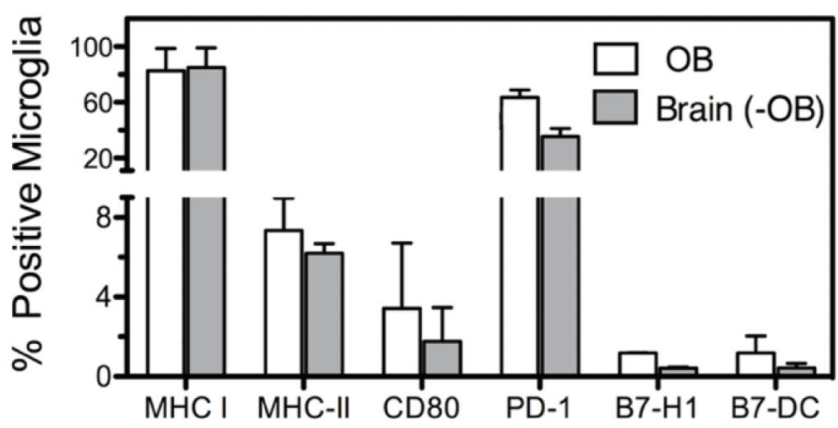

Figure 2.

Failure of OB microglia to express B7 costimulatory family members during the induction phase of VSV encephalitis. DTRTgF1 mice were either untreated (9 mice) or depleted of peripheral DCs (3 mice) and then given an intranasal application of VSV $\left(2 \times 10^{5} \mathrm{PFU} /\right.$ mouse). A third cohort (6 mice) was neither DT treated nor VSV infected (mock). Three days PI mice were euthanized and leukocytes isolated either from the OB or the remaining brain (-OB). (panel A) Microglia were defined as CD45 ${ }^{\text {low }} \mathrm{CD} 11 \mathrm{~b}+(\mathrm{R} 1)$ cells and assessed for co-expression of the indicated costimulatory molecules on OB microglia from mock infected (panels a-e), VSV infected (panels f-j) and VSV infected and DT treated (panels ko). (panel B) Distribution of B7 family members on microglia isolated from either the OB or whole brain devoid of $\mathrm{OB}$ (-OB). Microglia were phenotyped in two independent experiments and data expressed as the mean \pm SEM of the indicated family member. 


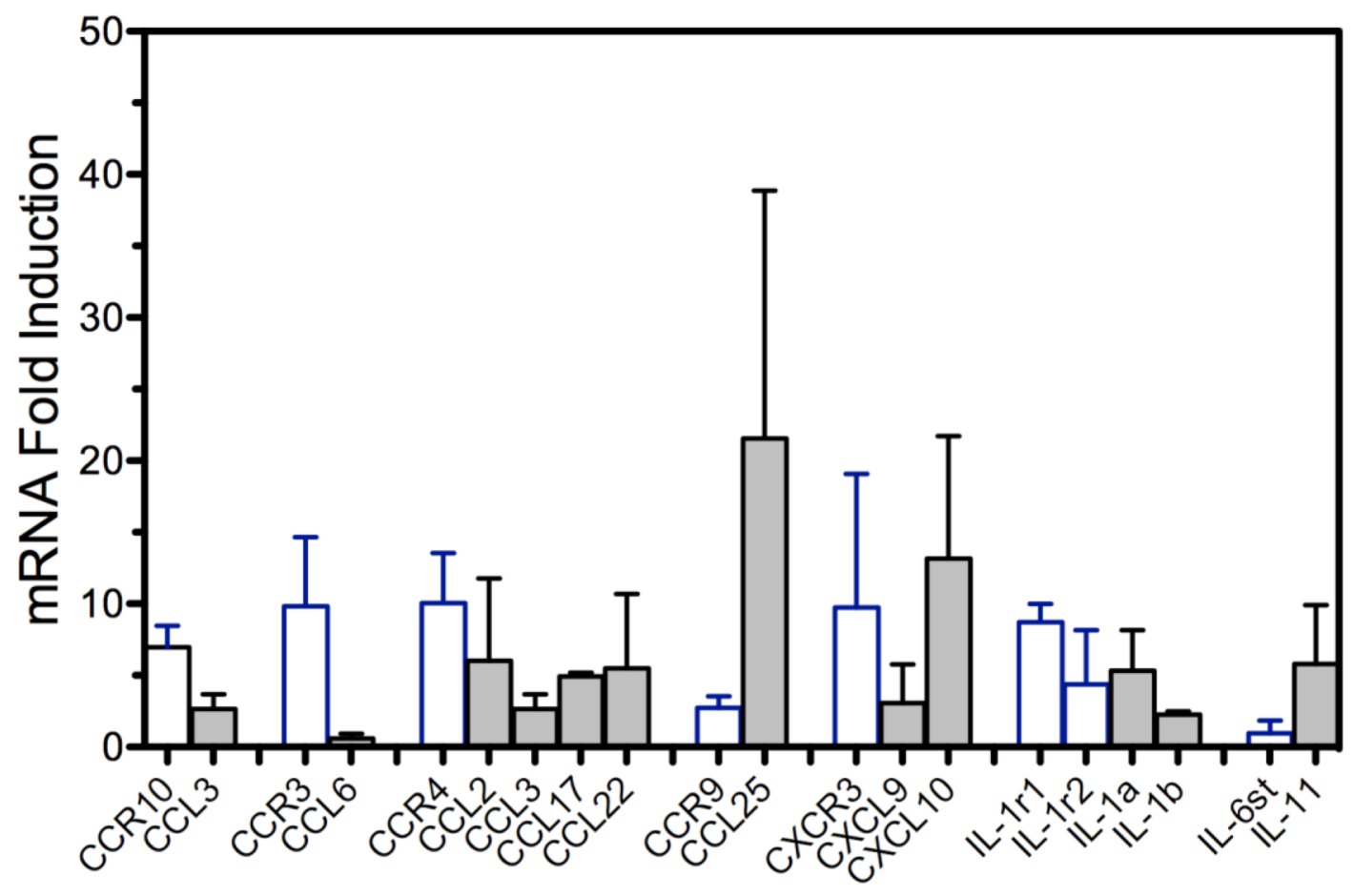

Figure 3.

VSV infection triggers rapid and multiple changes in brain chemokine and proinflammatory cytokine RNA profiles within 24hours of intranasal infection. Mice (5/group) were given a single intranasal application of $5 \times 10^{4}$ PFU of VSV and one day PI euthanized, perfused with PBS and whole brain homogenates prepared. RNA was isolated from individual mice, pooled and subsequently analyzed for chemokine and proinflammatory cytokine RNA levels using a commercial inflammatory cytokine qPCR array. Control (uninfected) mice were treated similarly and their brain RNA levels used to calculate fold increases/decreases in infected mice. Data represent the means +SEM of two independent experiments. 

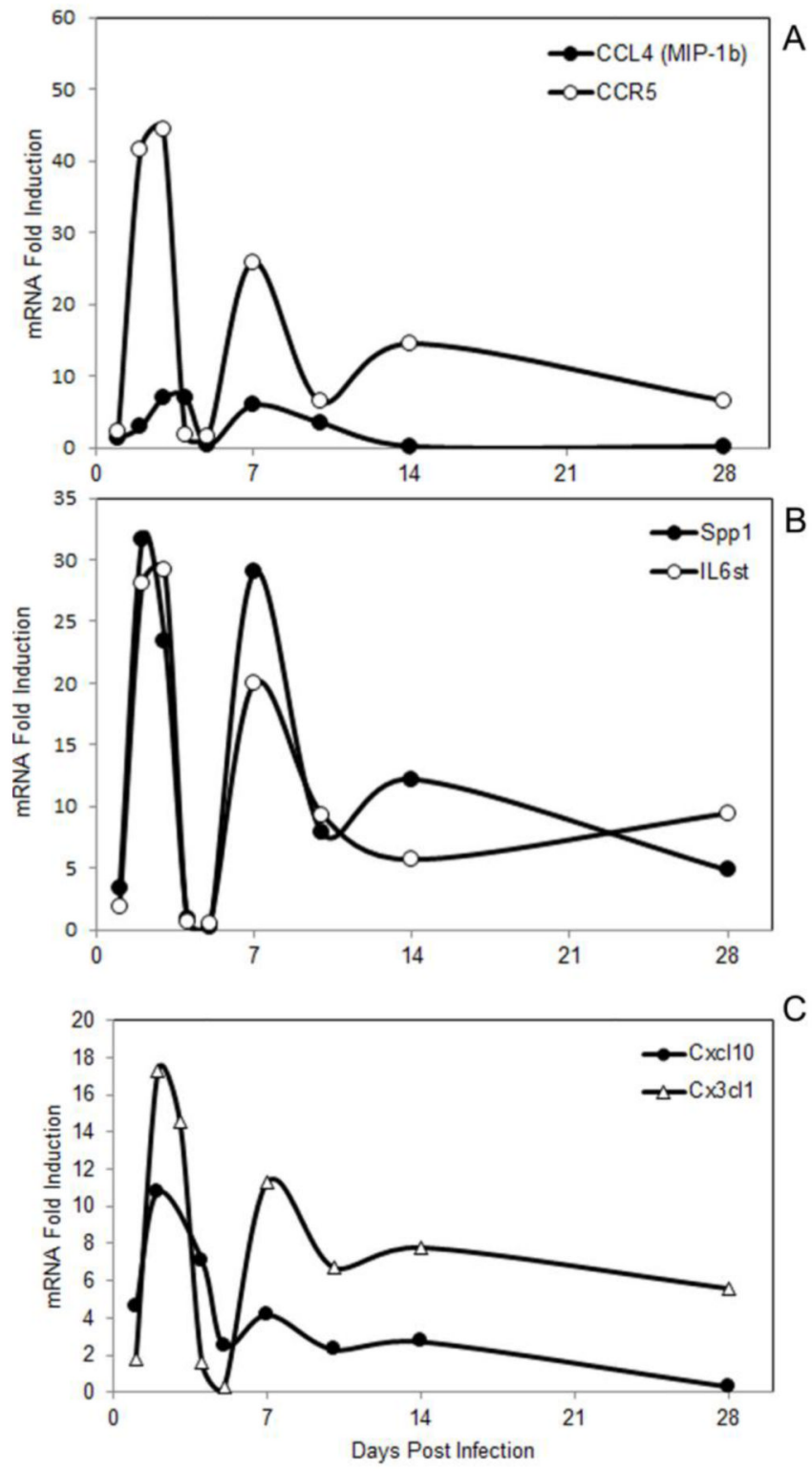

Figure 4.

Chemokine and proinflammatory cytokine responses display bimodal kinetics during VSV encephalitis. . Mice (3-5 mice/group) were given a single intranasal application of VSV and at the indicated time points, euthanized, perfused and whole brain homogenates prepared for subsequent analysis. RNA was isolated from each mouse, pooled and chemokine and cytokine profiles determiend as previously described. 

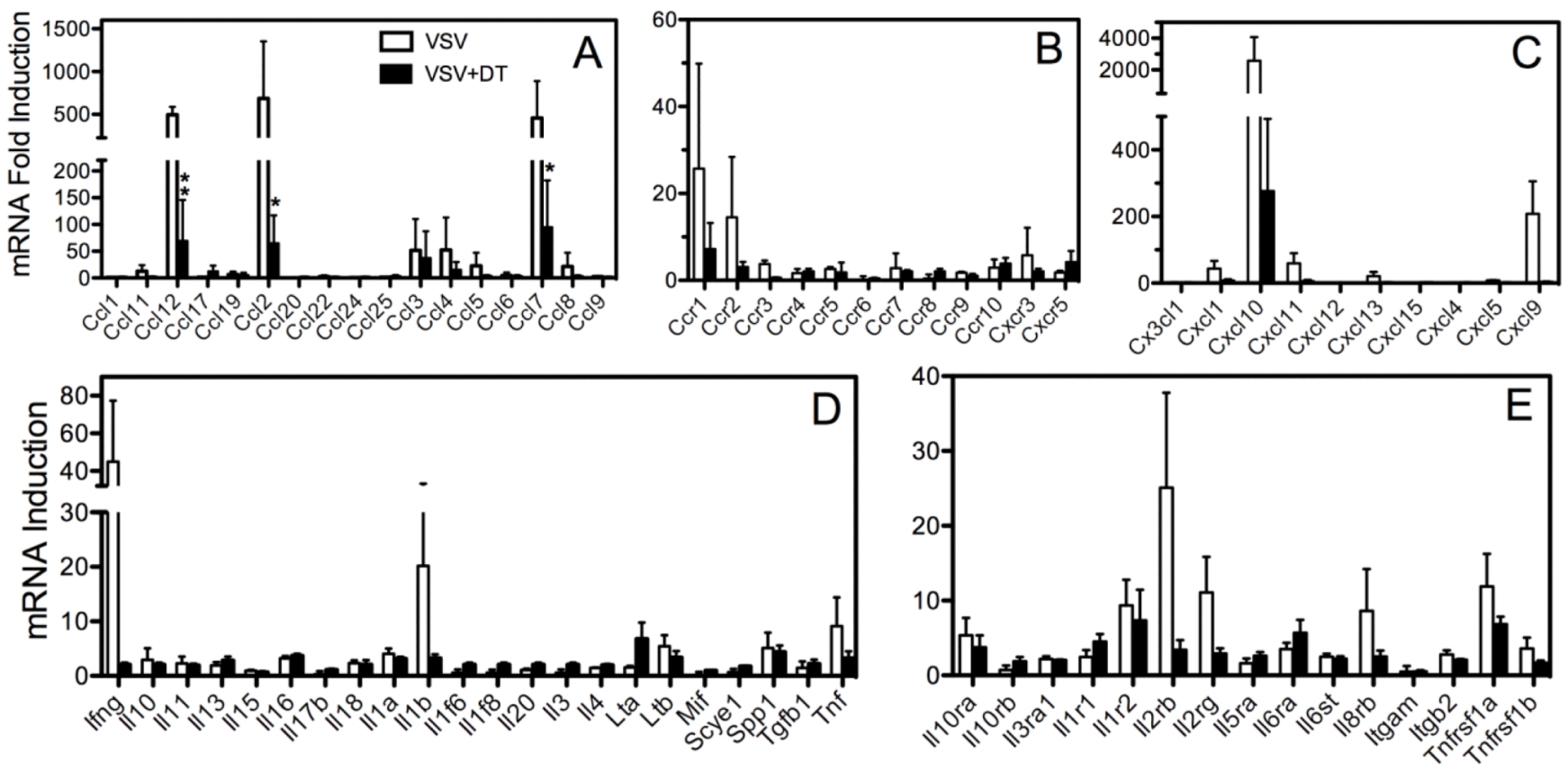

Figure 5.

Ablation of peripheral dendritic cells suppresses chemokine RNA levels in the brain during the acute phase of VSV encephalitis. DTRTgF1 mice were either untreated or treated with DT to deplete DCs and then infected intranasally with VSV. Six days PI mice were euthanized, perfused with cold PBS and brains evaluated for chemokine and proinflammatory cytokine mRNA levels by qPCR array. For each group individual profiles (3 mice/group) were determined and fold change calculated as previously described. Data shown are the mean \pm SEM. Asterisks indicate significant differences $(* \mathrm{p}=<0.05$, ** $\mathrm{p}=$ $<0.01)$ 

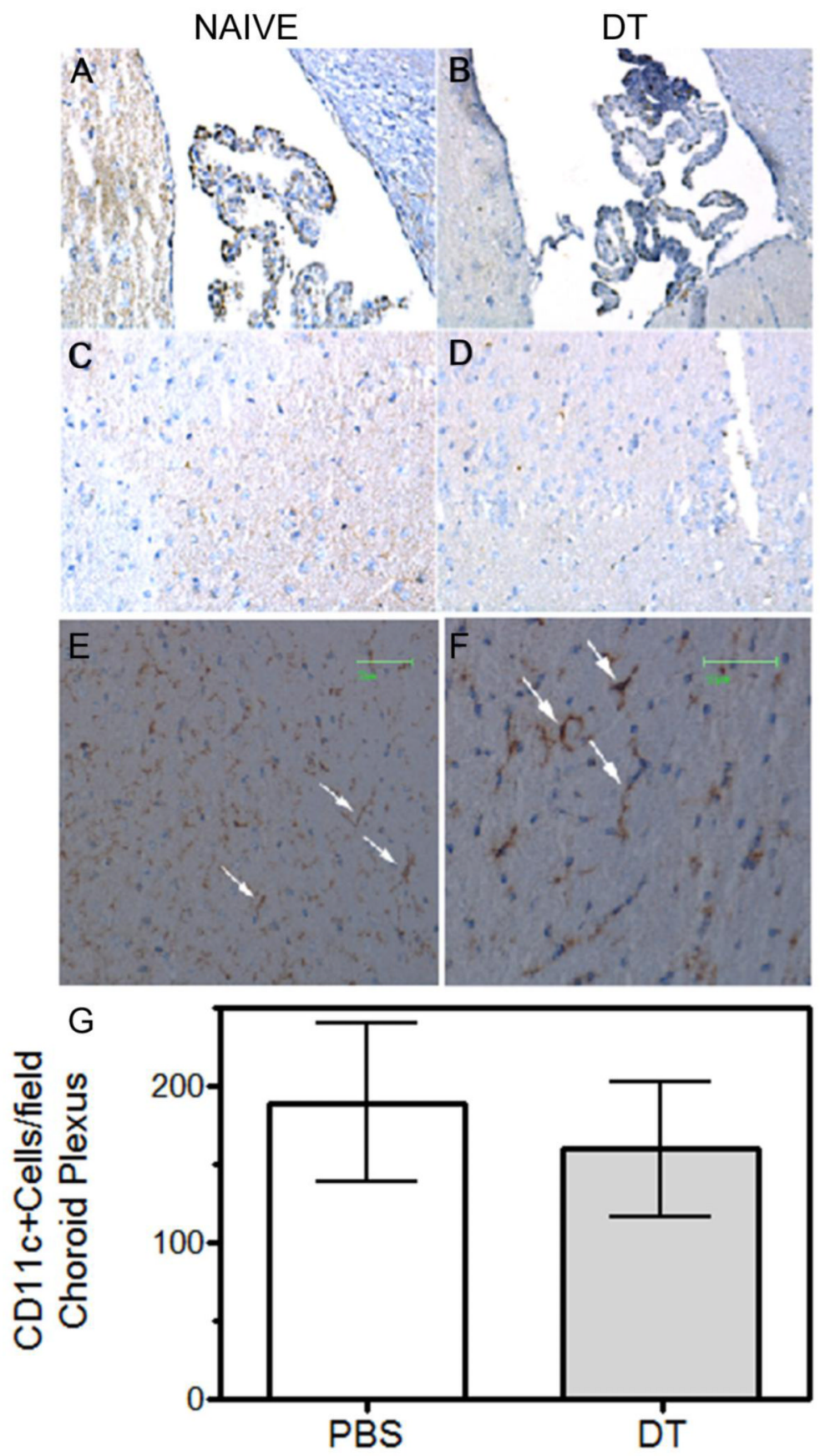

Figure 6.

Brain dendritic cells and perivascular macrophages remain following treatment with diphtheria toxin. DTRTgF1 mice were either untreated or given two doses of DT following our standard protocol. One day after the last injection, mice were euthanized and perfused with $\sim 30 \mathrm{mls}$ cold PBS. Brains were excised, halved along the longitudinal cerebral fissure dividing the brain into left and right hemispheres and half either snap frozen or fixed with $10 \%$ formalin. Frozen tissues were subsequently sectioned, stained with either CD11c (panels A-D) or F4/80 mAbs (panels E and F) followed by biotinylated secondary antibodies and avidin-biotinylated peroxidase (ABC kit, Vector Laboratories). Sagittal sections presented in this figure were obtained from $0-1.93 \mathrm{~mm}$ from the longitudinal cerebral fissure. 
Panels illustrate typical staining patterns of brain sections obtained from DTRTg mice treated with either PBS (panels A, C, E) or DT (B, D, F). Darkly stained F4/80+ cells in panels $\mathrm{E}$ and $\mathrm{F}$ are bPVMs (arrows). Lightly stained F4/80+ cells are parenchymal microglia. Frozen sections containing choroid plexus from PBS (panel A) and DT (panel B) injected mice (3-5 mice/group) were scored blindly for CD11+ cells and data expressed as mean \pm SEM (panel G). Two sections of the choroid plexus for each mouse were scored. Cell counts were not statistically different between treatment groups. 

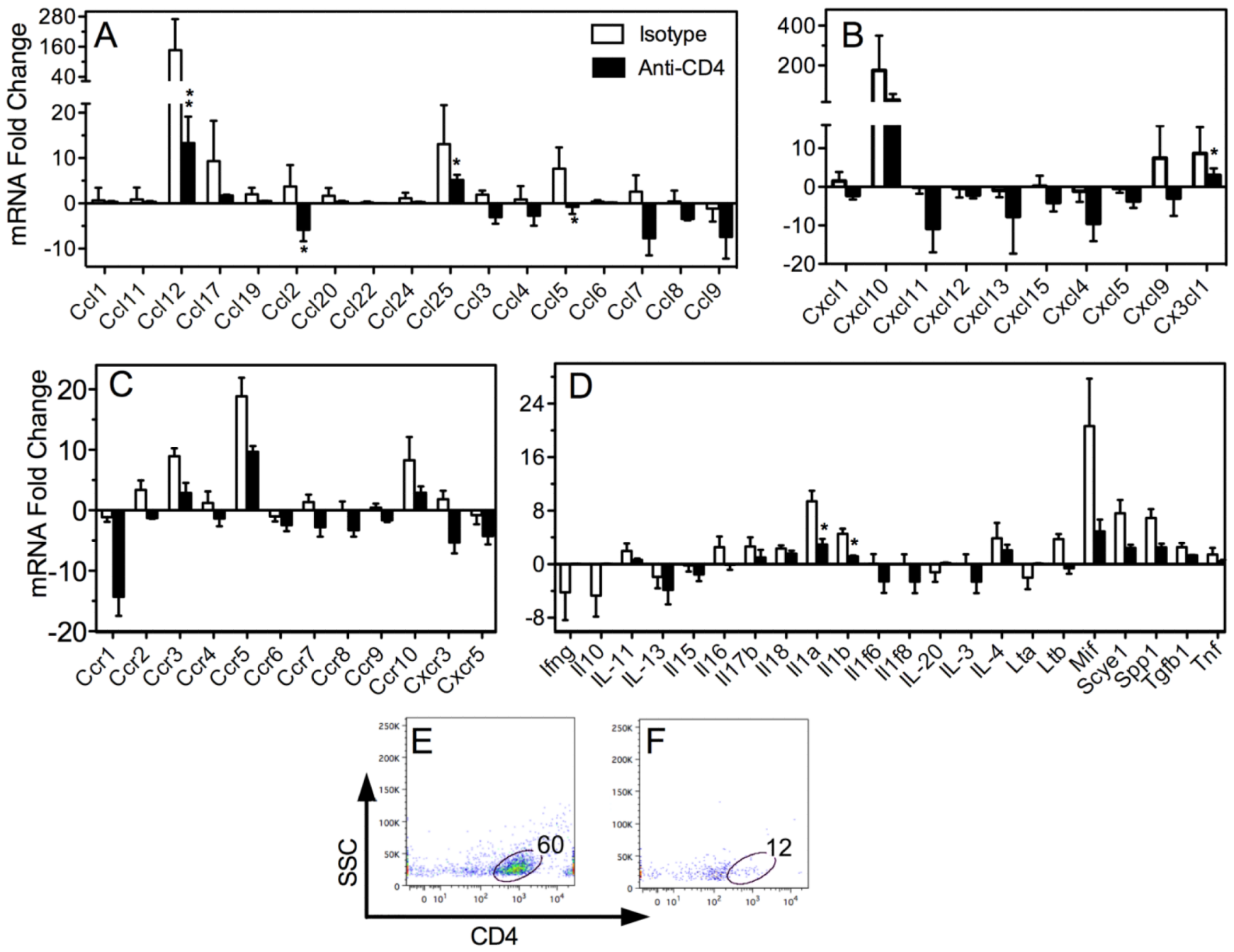

Figure 7.

$\mathrm{T}$ cell deficient mice mount blunted chemokine response during the acute phase of VSV encephalitis. MHC class I-deficient B6 mice (CD8 T cell deficient) were rendered CD4deficient using a depleting anti-CD4 mAb (details Materials and Methods). Control B6 mice were subjected to the same schedule except infused with a matched isotype control mAb. Seven days PI mice were euthanized, perfused with cold PBS and spleen and brains removed for flow cytometric and chemokine analysis, respectively. (panels A-D) Mean fold increases/decreases in RNA levels relative to levels detected in uninfected whole brains. Asterisks indicates significant differences $(* \mathrm{p}=<0.05, * * \mathrm{p}=<0.01$ ). (panels $\mathrm{E}, \mathrm{F})$ Infiltrating leukocytes were enriched from whole brain homogenates from mice treated with isotype control (panel E) or anti-CD4 mAb (panel F). Brain leukocytes were isolated, stained with anti-CD4 mAb and analysed by flow cytometry (see Materials and Methods). Percent CD4+ $\mathrm{T}$ cells in leukocyte gate are indicated. 


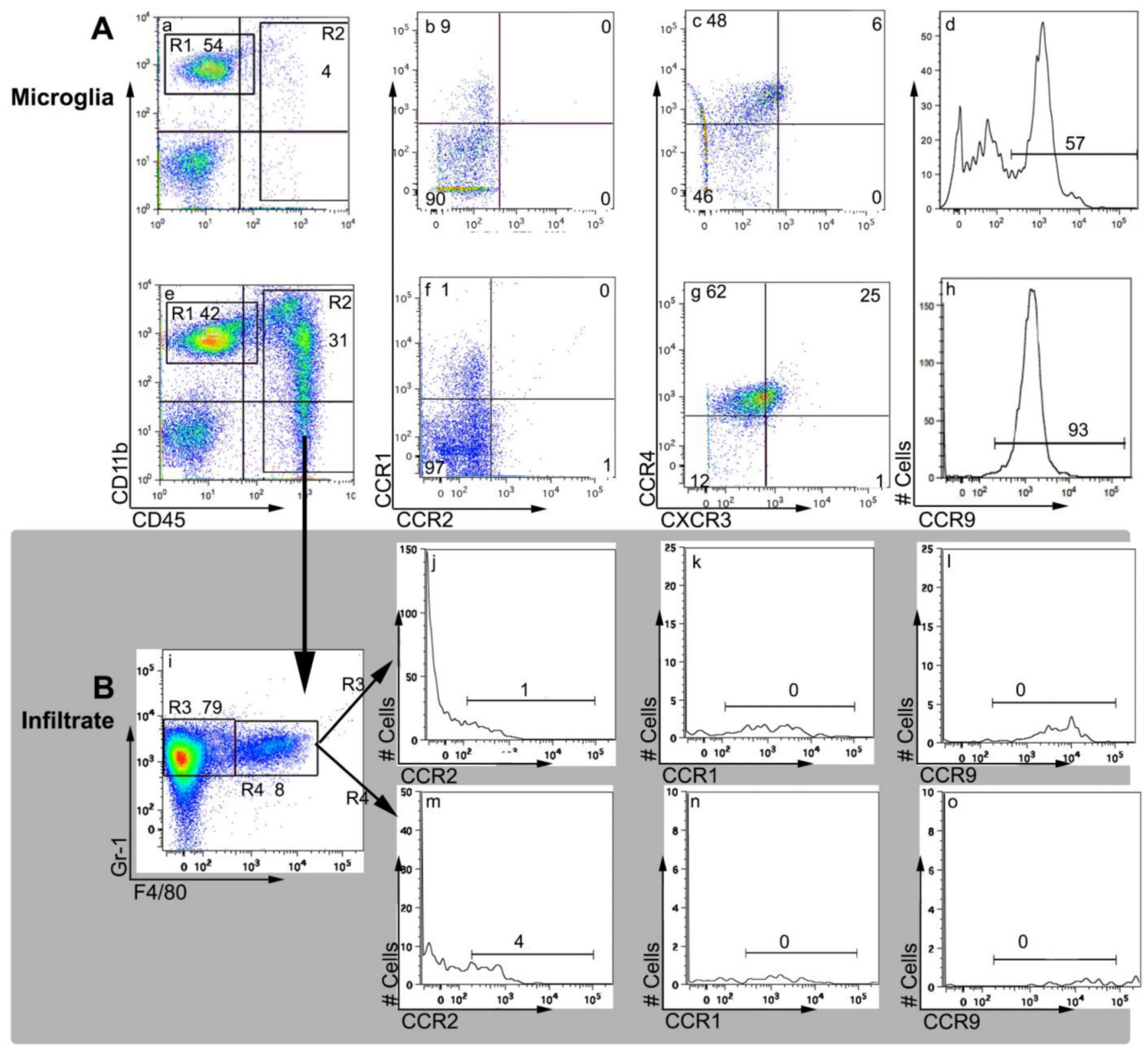

Figure 8.

VSV encephalitis is associated with a selective induction of chemokine receptors on microglia. B6 mice were given a single application of VSV and 7 days PI, mice were euthanized, perfused and whole brain homogenates prepared. Brain leukocytes were enriched on Percoll gradients and labelled with the indicated mAbs. (panel A) Leukocytes were isolated from uninfected (panels a-d) or VSV-infected brains (panels e-h) and identified by forward and side scatter characteristics. Microglia were gated as $\mathrm{CD} 45^{\text {low }} \mathrm{CD} 11 \mathrm{~b}+$ cells (region $1, \mathrm{R} 1$ ) and assessed for expression of the indicated chemokine receptors. (panel B) Inflammatory cells were identified in the $\mathrm{CD} 45^{\mathrm{high}} \mathrm{CD} 11 \mathrm{~b}+$ gate (panel e, R2) and within this gate granulocytes defined as $\mathrm{Gr}-1+\mathrm{F} 4 / 80-($ panel i, R3). Chemokine receptor profiles were then examined on this population (panels $\mathrm{j}-1$ ) as wells as a fourth population (R4) of double positive cells $(\mathrm{Gr}-1+\mathrm{F} 4 / 80+)$ presumed to be 
macrophages (panels m-o). This experiment was repeated a second time and yielded similar results. 